\title{
El canon de control de vertidos estatal y los cánones de saneamiento autonómicos. Breve apunte de derecho comparado alemán. II $^{*}$
}

\author{
Marta Oller Rubert \\ Becaria del Instituto Euromediterráneo de Hidrotécnia \\ Departamento de Derecho Público. Área de Derecho Administrativo \\ Universidad Jaume I (Castellón de la Plana)
}

Sumario: I. INTRODUCCIÓN. II. RÉGIMEN JURÍDICO DEL CANON DE CONTROL DE VERTIDOS ESTATAL. III. CONCURRENCIA ENTRE EL CANON ESTATAL Y LOS CÁNONES DE SANEAMIENTO AUTONÓMICOS. IV. CONCLUSIONES.

\section{INTRODUCCIÓN}

Ante la situación actual del estado cualitativo de nuestras aguas -que llegó sobre todo en décadas pasadas, no muy lejanas, a su nivel máximo de degradación ${ }^{1}$, y que parece ser se está recuperando gracias a la actual y notable conciencia ecológica popular ${ }^{2}$ - se hace imprescindible, dado el elevado gasto que ello comporta, considerar la importancia de los instrumentos económicos y financieros como uno de los medios, puede afirmarse, de los que hasta ahora se han mostrado efectivos para incentivar a los usuarios a producir una menor cantidad de residuos ${ }^{3}$ y obtener una

\footnotetext{
* Al haberse producido diversos errores de imprenta en el artículo del mismo título que aparece en el n. ${ }^{\circ} 294-295$, pp. 485-520 y existiendo la necesidad de actualizar la legislación que se cita aprobada durante la fase de impresión, se reproduce debidamente corregido y revisado dicho artículo.

${ }^{1}$ Ejemplo de ello fue la utilización el Rin como vertedero común en Europa central como señaló expresamente el Ministro Federal de Medio Ambiente Protección de la Naturaleza y Seguridad Nuclear, JuRgEN TRITTIN en «Der Wassersektor in Deutschland, Methoden und Erfahrungen», p. 1. Disponible en: www.umweltbundesamt.org/wsektor. En este sentido, en el año 2001, se ofrecían como cifras más que significativas del transporte por el río Rin las siguientes: 90.000 toneladas de contaminantes, entre ellas 1.000 toneladas de arsénico, 200 toneladas de cadmio, 29.000 toneladas de cobre... entre otras sustancias calificadas como muy peligrosas. Fuente: K. EGGNESTEIN, «La contaminación de ríos, lagos y mares», 2001. Disponible en: www.j-lorber.de/kes/6/e-contam.htm.

2 Así se desprende del informe de la Agencia europea de Medio Ambiente «El agua en Europa: una evaluación basada en indicadores. Resumen» de 2003. Disponible en: http://reports.es.eea. eu.int/report_2003_0617_150910/es/index_html_local. Con fecha de 11 de septiembre se ha publicado, en inglés, el informe de 2005: http://reports.eea.eu.int/eea_report_2005_4/en/outlook_ web.pdf.

3 Vid. F. KIRCHHOF, «Umweltabgaben-Die Regelungen in der Europäischen Gemeinschaft und ihren Mitgliedstaaten» en Handbuch zum europäischen und deutschen Umweltrech, Allgemeine Umweltrecht, Band I. Rengeling (Hrsg.), EUDUR, 2003, p. 1337.
} 
consiguiente reducción de los mismos, alcanzándose, de este modo, un nivel de calidad aceptable y a la par exigido, con una máxima perentoriedad, desde instancias europeas ${ }^{4}$.

Justamente este deficiente nivel cualitativo de las aguas le ha valido denuncias por parte de la Comisión no sólo a nuestro país ${ }^{5}$ quien, junto con Bélgica y el Reino Unido, en base al artículo 226 del Tratado, fue llevado ante el Tribunal de Justicia por incumplir con el plazo de diciembre de 2000 para incorporar la Directiva sobre las aguas destinadas el consumo humano ${ }^{6}$, sino también a otros países como Francia $^{7}$ o Alemania ${ }^{8}$, que han supuesto a los Estados Miembros sus correspondientes resoluciones negativas por parte de la Comisión Europea. Ésta es, pues, la línea seguida e impuesta a los Estados Miembros desde la Unión Europea. Es por

${ }^{4}$ Merece ser destacada la misma inquietud que el profesor EMBID IRUJo manifiesta en relación con los aspectos económicos vinculados a la utilización del agua, en «Evolución del derecho y de la política del agua en España», $R A P$, n. $^{\circ} 156$, Septiembre-Diciembre 2001, pp. 86 y ss. Así, ejemplos de la cercanía de plazos y del interés de la Comunidad por establecer y cumplir los objetivos ambientales se reflejan en la Directiva 91/271 que fija como fecha límite el 31 de diciembre de 2005; por otra parte, la Directiva 2000/60 establece que a partir de 2010 los Estados miembros deberán garantizar que la política de tarificación incite a los consumidores a utilizar los recursos de forma eficaz y que los diferentes sectores económicos contribuyan a la recuperación de los costes de los servicios relacionados con el uso del agua, incluidos los costes medioambientales y de gestión de recursos.

${ }^{5}$ A pesar del intento de solucionar esta situación por parte de nuestro país que, a fin de paliar la posible sanción, remitió un proyecto de parte de esta legislación requerida.

España también ha sido denunciada y condenada por la Sentencia de 25 de noviembre de 2003 del Tribunal de Justicia de las Comunidades Europeas por el incumplimiento de la Directiva 76/160/CEE sobre la calidad de aguas para el baño. A fecha de enero de 2005 existían contra España cinco procedimientos de infracción de normativa ambiental comunitaria, uno de ellos debido a un problema de contaminación del agua de la playa de Sueca (Valencia). Fuente: Medio Ambiente en Europa, n. ${ }^{\circ}$ 91, 21 de enero de 2005. Disponible en: www.juntadeandalucia.com.

${ }^{6}$ Al respecto las Sentencias del Tribunal de Justicia de las Comunidades Europeas de 5 de julio de 1990 (Asunto 42/89, Comisión contra el Reino de Bélgica), de 11 de junio de 1991 (Asunto 290/89, Comisión contra el Reino de Bélgica), de 22 de abril de 1999 (Asunto C-340/96, Comisión contra Reino Unido e Irlanda del Norte).

${ }^{7}$ Que ha sido objeto de tres pronunciamientos de la Comisión. El primero de ellos relativo al incumplimiento de los plazos de diciembre de 2000 para incorporar a su legislación nacional la nueva directiva sobre aguas destinadas al consumo humano, el segundo se debió a la no entrega de los informes relativos a los resultados de los análisis de las aguas de baño durante el año 1999, y el tercero de los pronunciamientos por el cual se llevó a Francia ante el Tribunal de Justicia, en virtud del artículo 226 del Tratado, se refería a los vertidos contaminantes que causaron deterioro en el lago salado de Berres (Bouches du Rhone). Fuente: www.waternunc.com/esp/dg11s16_2002.htm.

${ }^{8}$ Sentencia de 11 de noviembre de 1999. Asunto 184/97, Comisión c. Alemania por el incumplimiento de la Directiva 76/464/CEE sobre contaminación de aguas. 
ello, que por la actualidad del tema y constatada la existencia de estos instrumentos económicos en nuestro ámbito, tanto a nivel nacional como autonómico y en el resto de los Estados Miembros, que se trata a continuación de ofrecer algunas reflexiones sobre estas figuras tributarias: los cánones de saneamiento.

En nuestro estudio se toma como referencia la República Federal Alemana dada la alta, una de las mayores a nivel europeo, contaminación de sus ríos ${ }^{9}$ y también por su gran sensibilidad y preocupación, desde hace muchas décadas, por la protección del medio ambiente. En consecuencia ha desplegado un sistema de protección del medio ambiente notablemente desarrollado acompañado, a su vez, por un sistema de responsabilidad y sancionador que podríamos calificar de muy estricto, amén de recoger expresamente en su Constitución el principio de desarrollo sostenible al señalar el art. 20.a) Grundgesetz (Constitución alemana) que el Estado debe cumplir la protección del medio ambiente: «teniendo en cuenta su responsabilidad por las generaciones futuras». Así, cualquier persona que contamine el agua sin la correspondiente autorización está sometida a las penas fijadas en su Código Penal. A ello hay que sumar las responsabilidades civiles, donde por una parte se contemplan las responsabilidades por daños a las aguas y por otra las responsabilidades por daños al medio ambiente.

En cuanto al desarrollo de este artículo -el estudio de los cánones que gravan el mal uso y la disminución de la calidad de las aguas- se requiere en primer lugar realizar una breve reseña acerca de sus orígenes para definir cuál es la situación actual. Así, la positivación de los cánones en las legislaciones nacionales responde a las recomendaciones internacionales y europeas, como ya adelantábamos. Siguiendo dichos postulados, España, ya en la Ley de Aguas, de 2 de agosto de 1985, estableció un régimen de vertidos que contemplaba la figura del canon, régimen que se vio notablemente modificado por la Ley 46/1999, de 13 de diciembre, a partir de la cual se estableció una regulación más estricta del mismo, refundiéndose todas estas innovaciones en el vigente Real Decreto Legislativo $1 / 2001$, de 20 de julio $^{10}$. A estas normas hay que añadir los respectivos

\footnotetext{
9 Vid. Nota 1.
}

${ }^{10}$ BOE de 24/07/01. Modificado por la Ley 24/2001, de 27 de diciembre, de Medidas Fiscales, Administrativas y del Orden Social, por la Ley 16/2002, de 1 de julio, de prevención y control integrados de la contaminación, por la Ley 53/2002, de 30 de diciembre, de Medidas Fiscales, Administrativas y del Orden Social, por la Ley 62/2003, de 30 de diciembre, de medidas fiscales, administrativas y del orden social, por la Ley $11 / 2005$, de 12 de junio, por la que se modifica la Ley 10/2001, de 15 de julio, del Plan Hidrológico Nacional. 
reglamentos de desarrollo, el Reglamento del Dominio Público Hidráulico $^{11}$ y el Reglamento de la Administración Pública del Agua y de la Planificación Hidrológica ${ }^{12}$, y la normativa autonómica correspondiente.

Por su parte, en la República Federal alemana existen dos leyes marco estatales que conforman los dos pilares fundamentales del derecho de aguas: la Wasserhaushaltsgesetz ${ }^{13}$ y la Abwasserabgabengesetz ${ }^{14}$; esta última, de forma expresa desde 1976 regula, a modo de marco, la figura del canon de aguas residuales (Abwasserabgabe). Sin embargo hemos de aclarar que se establece únicamente un régimen jurídico mínimo de esta figura, de forma que cada Land posee además disposiciones relativas a los cánones de saneamiento que concretan la Abwasserabgabengesetz, y también pueden aprobar sus propias Leyes del Agua válidas en su ámbito territorial, Landeswassergesetze.

Seguidamente se ofrecen unas reflexiones sobre algunos de los muchos temas y cuestiones que plantean tanto la naturaleza jurídica de estos tributos y la conducta gravada a través de los mismos, así como la incardinación del canon estatal con los cánones autonómicos.

\section{RÉGIMEN JURÍDICO DEL NUEVO CANON DE CONTROL DE VERTIDOS ESTATAL}

El Texto Refundido de la Ley de Aguas ha mantenido la figura del canon de vertido que es una concreción del principio «quien contamina, paga» y que se recogió ya en 1985 en el art.105 de la Ley de Aguas entonces como único testigo a nivel estatal en nuestro ordenamiento jurídico de tal postulado ${ }^{15}$. Igualmente este principio aparece, desde 1971, anunciado

\footnotetext{
11 RD.849/1986, de 11 de abril. BOE de 30/04/86. Modificado por el RD. 606/2003, de 23 de mayo.

12 RD. 927/1988, de 29 de julio. BOE de 31/08/88.

13 En adelante $W H G$, de 27 de junio 1957, nueva redacción de 19.8.2002, BGB1 I, p. 3245. Esta Ley ha sido recientemente modificada por el art.2 de la Ley de 25 de junio de 2005, BGB1, 2005, p.1746.

14 En adelante $A b w A G$, de 13.09.1976, entró en vigor el 2 de enero de 1978. La satisfacción del canon fue obligatoria a partir del 1 de enero de 1981. Esta Ley, dictada en base a lo dispuesto en el art. 75.1.4 GG, ha sido modificada en varias ocasiones, siendo el texto vigente en la actualidad la versión publicada el 18 de enero de 2005.

15 Según Fuentes Bodelón este principio no se configura como la típica responsabilidad civil sino como un aseguramiento de que los costes de las medidas ambientales no recaigan sobre la Administración, puesto que el contaminador desde esta perspectiva sólo viene obligado a controlar la contaminación hasta el límite que fije el Gobierno o la Administración, asignando al sujeto pasivo el coste de reducir la contaminación al nivel fijado por la Administración, vid. «Incentivos medioam-
} 
en el primer Programa de Medio Ambiente del Gobierno Federal Alemán como elemento de la nueva política de protección del medio ambiente ${ }^{16} \mathrm{e}$ inspira también el establecimiento del Abwasserabgabe en este país ${ }^{17}$. Este principio también lo encontramos en el ámbito europeo donde se consagró expresamente en el art.174.2 de la versión consolidada del Tratado de la Comunidad Europea ${ }^{18}$.

El régimen de vertidos en nuestro país contenido en principio en las Leyes de Aguas que se han venido sucediendo, acompañadas de los reglamentos de desarrollo, se ha visto en los últimos años afectado con la aparición de diversas normas: en primer lugar, y en transposición de la Directiva 96/61, de 24 de septiembre, relativa a la prevención y al control integrados de la contaminación ${ }^{19}$, por la aprobación de la Ley 16/2002, de 1

bientales en la CEE», en Revista de Derecho Ambiental, n. ${ }^{\circ}$ 6, 1990, p. 31. Más recientemente la Directiva 99/31/CE relativa al vertido de residuos considera que en virtud del principio de «quien contamina, paga» es necesario tener en cuenta, entre otros factores, el daño al medio ambiente que causan los vertidos, obligando expresamente a los estados a que garanticen todos los costes que ocasione el establecimiento y explotación de vertederos, incluyendo el coste de la fianza, del cierre y mantenimiento posterior. Vid. el Considerando 5, y el art.10 de la Directiva 99/31/CE del Consejo, de 26 de abril de 1999, relativa al vertido de residuos. DOCE 16/7/99, Serie L n. ${ }^{\circ} 182$. El Parlamento europeo aprobó, en su sesión de 31 de marzo de 2004, la Directiva 2004/35/CE, del Parlamento Europeo y del Consejo, de 21 de abril de 2004, sobre responsabilidad medioambiental en relación con la prevención y reparación de daños medioambientales. DOCE 30/04/04. Serie L 143/56.

16 Vid. BT-Drucks VI/2710,11, 35 y 37.

17 Vid. LaSKOwSKI, C. S.R/ZIEHM, «Gewässerschutzrecht« en Umweltrecht, Koch, op.cit, p. 219.

${ }^{18}$ El Consejo de la OCDE, en sesión de 14 de noviembre de 1974, desarrolló este principio precisando su campo de acción y poniendo de relieve la urgencia en su puesta en práctica. La introducción del principio no se hizo esperar como reflejó el informe del Comité de Medio Ambiente de la OCDE de 23 de noviembre de 1981. Así el IV Programa de Acción Ambiental (1987-1992) introdujo este principio como justificación de los incentivos económicos y fiscales, y el $V$ Programa (1992-1999) lo consolidó. El actual VI Programa (2002-2012) toma de nuevo como punto de partida los principios de «cautela», «acción preventiva» y «quien contamina, paga». Vid. B. LozANO Cutanda, Derecho Ambiental Administrativo. Dykinson, Madrid, 2003, pp. 225- 233.

19 La Directiva 96/61, en un intento de superar la sectorialización que existe en esta materia, trata la contaminación de origen industrial desde una perspectiva global, dando así cumplimento al mandato del art.130.R del Tratado (que recoge la tutela ambiental), ya que la prevención sectorializada, lo que hace es que los riesgos se trasladen de un sistema a otro. Se trata, de esta forma, de conseguir una mayor protección en todos los frentes: aire, agua y suelo. En nuestra legislación un ejemplo de este tratamiento integral de prevención de la contaminación se encontraba en la derogada Ley 20/1986, de 14 de mayo, básica de Residuos Tóxicos y Peligrosos (actualmente esta Ley está derogada por la Ley 10/1998, de 21 de abril, de Residuos, BOE de 22/04/98), que aunque exclúa de su ámbito de aplicación el tema de los efluentes y vertidos al alcantarillado o a los cursos de agua regulados en la Ley de Aguas, su art. 3.2, en conexión con el art. 6.3, imponía que en las operaciones de gestión de dichos vertidos no se trasladase la contaminación o el deterioro ambiental a otro medio 
de julio, de Prevención y Control Integrados de la Contaminación ${ }^{20}$ (LPCIC), y la posterior aprobación y también necesaria transposición ${ }^{21} \mathrm{de}$ la Directiva Marco del Agua aprobada el 23 de octubre de 2000 (DMA) que en nuestro Derecho de aguas ha supuesto la reforma y adecuación a los postulados comunitarios del Texto Refundido de la Ley de Aguas por la Ley 62/2003, de 30 de diciembre, de medidas fiscales, administrativas y del orden social, y la Ley $11 / 2005$, de 22 de junio, por la que se modifica la Ley 10/2001, de 5 de julio, del Plan Hidrológico Nacional; así como la modificación del Reglamento de dominio público hidráulico de 1986, por Real Decreto 606/2003, de 23 de mayo ${ }^{22}$. Reformas de las que también se tiene constancia en la adaptación a los mandatos europeos del ordenamiento jurídico de las aguas alemán reflejadas, en cuanto al orde-

receptor, puesto que, efectivamente, con el tratamiento y depuración del agua no terminan los problemas ambientales relativos a la eliminación de residuos, sino que éstos, más bien, se trasladan o se transforman, como puede ser el caso de los lodos generados por la depuración de aguas urbanas, que son almacenados cuando se ha investigado el carácter orgánico de su composición, y que permitiría su reutilización en el sector agrario como fertilizantes. Además, debe tenerse en cuenta la aprobación de la Directiva 2003/35, de 26 de mayo, por la que se establece medidas de participación del público en la elaboración de determinados planes y programas relacionados con el medio ambiente y por al que se modifica, en lo que se refiere a la participación del público y el acceso a la justicia, las Directivas $85 / 337$ y 96/61. Siendo la fecha límite de transposición el 25 de junio de 2005. DO L 156, de 25 de junio de 2005.

${ }^{20}$ BOE de 2/07/02. La transposición de la Directiva 96/61/CE se realizó, pues, con más de dos años de retraso, circunstancia que le valió a nuestro país la condena por parte del Tribunal de Justicia de las Comunidades Europeas, en la Sentencia de 7 de marzo de 2002, Comisión v. España (Asunto C29/01).

Esta Ley ha sido calificada en España como la «Ley General del Medio Ambiente». La ley obliga a las instalaciones industriales existentes a una profunda adaptación tecnológica, que supone la incorporación de las mejores técnicas disponibles (MTD) en cada sector de actividad, que permitirán cumplir los valores límite de emisiones contaminantes. Sobre esta Directiva, vid. G. VALENCIA MARTíN, «El régimen jurídico de control integrado de la contaminación» CISS, Noticias de la Unión Europea, n. ${ }^{\circ} 153$, 1997; J. PÉREZ FERNÁNDEZ, «La Directiva relativa a la prevención y control integrado de la contaminación (IPPC) 96/61/CE, del Consejo, de 24 de septiembre: su contenido» en Revista de Derecho Urbanístico y Medio Ambiente, Diciembre, 2000; Lasagabaster Herrarte/García Ureta /Lazcano Brotons. Derecho Ambiental. Parte General, IVAP, Bilbao, 2004, pp. 191 y ss, entre otros.

La aprobación de esta Ley supuso, además, la modificación y adecuación a la nueva autorización ambiental integrada del TRLAg que afectó al art. 105 y a la Disposición adicional 10.

${ }^{21} \mathrm{El}$ art. 24 DMA establece un plazo de transposición en las legislaciones nacionales que se agotó el 22.12.2003, y que se vio satisfecho, con retraso, tras la aprobación de la Ley 62/2003, de 30 de diciembre, de medidas fiscales, administrativas y del orden social (BOE de 31/12/03, pp. 4687446992).

${ }^{22}$ Que como él mismo señala «... tiene en cuenta la Directiva-Marco del Agua de la Unión Europea y el Plan Hidrológico Nacional». 
namiento hídrico, en la $6^{\mathrm{a}}$ Novelle que introdujo en el Derecho alemán el concepto de la «mejor tecnología disponible» en el campo de los vertidos de aguas residuales ${ }^{23}$ y en la $7^{\text {a }}$ Novelle de la WHG que traspuso la citada Directiva Marco del Agua ${ }^{24}$.

Las anteriores normas van a influir, notablemente, en varios aspectos, especialmente en nuevos planteamientos de acciones integradas en la protección de la calidad de las aguas, como demuestra la implantación del nuevo régimen administrativo español de los vertidos de aguas residuales procedentes de la industria, por lo que respecta al nuevo sistema de autorizaciones. En efecto, con la aprobación de la nueva LPCIC va a existir para las actividades industriales incluidas en el Anexo $\mathrm{I}^{25}$ una única autorización de carácter ambiental ${ }^{26}$ (denominada autorización ambiental integral ${ }^{27}$ ), que incluye expresamente a las autorizaciones de vertidos a las aguas continentales y al dominio público marítimo terrestre, desde tierra al mar ${ }^{28}$. La trascendencia de las autorizaciones, como instrumento necesario para la prevención de la contaminación, es evidente pues, como veremos, si bien la existencia de éstas no es requisito indispensable para resultar sujeto activo del canon, sí lo será para determinar cuestiones tan trascendentes como el

23 Modificación que entró en vigor en noviembre de 1996. BGB1, pp. 1695-1711.

${ }^{24}$ La reforma de la $W H G$ se dispuso por el art.1 de la Ley de 18.06.2002, que entró en vigor el 25.06.2002 (BGB1 I, p. 2711) y supuso una nueva redacción de la WHG, publicada el 19.08.2002 BGB1 I. p.3245, que entró en vigor el 21.08.2002.

${ }^{25}$ Con las excepciones a las que se refiere el art.2 LPCIC.

${ }^{26}$ La Ley prevé en la Disposición Transitoria Primera un periodo de adaptación para las instalaciones ya existentes (Vid. art.3.d), que se extiende hasta el 30 de octubre de 2007.

27 El art.3.a) de la Ley define la AAI como «la resolución del órgano competente de la Comunidad Autónoma en la que se ubique la instalación, por la que se permite, a los solos efectos de la protección del medio ambiente y de la salud de las personas, explotar la totalidad o parte de una instalación, bajo determinadas condiciones destinadas a garantizar que la misma cumple el objeto y las disposiciones de esta Ley. Tal autorización podrá ser válida para una o más instalaciones que tengan la misma ubicación y sean explotadas por el mismo titular». Sobre la AAI realiza un análisis detallado C. Chinchilla Martín en su artículo «La autorización ambiental integrada: La Ley 16/2002, de 1 de julio, de prevención y control integrados de la contaminación» en Revista Andaluza de Administración Pública, Julio-Agosto, 2002, pp. 51 y ss.

${ }^{28}$ El art.11.1.b) de la LPCIC dice: «1. La finalidad de la autorización ambiental integrada es: disponer de un sistema de prevención y control de la contaminación, que integre en un solo acto de intervención administrativa todas las autorizaciones ambientales existentes en materia de producción y gestión de residuos, incluidas las de incineración de residuos municipales y peligrosos y, en su caso, las de vertido de residuos; de vertidos a las aguas continentales, incluidos los vertidos al sistema integral de saneamiento, y de vertidos desde tierra al mar, así como las determinaciones de carácter ambiental en materia de contaminación atmosférica, incluidas las referentes a los compuestos orgánicos volátiles». 
importe del mismo. La figura de la autorización en Alemania también ha tenido que adaptarse a los nuevos mandatos europeos, fruto de ello fue necesario modificar el BImSchV (Verordnung zur Durchführung des $B i m S c h G^{29}$ ) regulándose el procedimiento integral para la concesión de dichas autorizaciones en los art. 4 y 13 de la BundesImmissionsschutzgesetz $(B i m S c h G)^{30}$, en el que se excluye de este proceso integral al régimen de aplicación general de los arts. 7 y 8 de la $W H G^{31}$ y, en particular, en cuanto al ordenamiento hídrico se hizo necesaria la aprobación de la $6^{\mathrm{a}}$ Novelle $^{32}$ de la Ley de aprovechamientos del agua ${ }^{33}$, que afectó al contenido del art.7.a) $W H G^{34}$ relativo a las autorizaciones para la realización de vertidos de aguas residuales. Así, en la Ley de aprovechamientos del agua alemana $(W H G)$ existe una parte importante de su articulado dedicado a ordenar estas figuras, en concreto los artículos 6 a $13 W H G$, posteriormente desarrollados reglamentariamente por la Abwasserveordnung ${ }^{35}$, que establece que sólo se concederá dicha autorización si se comprueba que la carga de contaminación de las aguas residuales se mantiene tan baja como es posible usando la mejor tecnología posible (Beste verfügbare Technik) ${ }^{36}$.

\footnotetext{
${ }^{29}$ Reglamento sobre inmisiones. En cuanto a estos reglamentos fueron modificados el 4.BImschV (Verordnung über genehmigungsbedürftige Anlagen), y el 9. BImschV (Verordnung über das Genehmigunsverfahren).

${ }^{30}$ Ley federal de inmisiones. La trasposición de la Directiva 96/61 se realizó por la Artikelgesetz de 27 de julio de 2001, BGB1, Nr. 40, de 2.08.2001. pp. 1950-2021. Nueva redacción vigente desde el 26.09.2002. (BGBl. I Nr. 71 de 04.10.2002, p. 3830).

${ }^{31}$ Aunque desde algunas voces se reclama la trasposición también en dicho ámbito (arts.7 y 8 WHG) del art.7 de la Directiva 96/61, dado que el proceso regulado en estos artículos no participan las autoridades autorizatorias establecidas en el ordenación de inmisiones. Vid. B. BADER, «Die Umsetzung der IUV-Richtlinie in deutsches Recht. Probleme und Chancen» en Inaugural-Dissertation zur Erlangung der Doktorwürde einer Hohen Rechtswissenschaftlichen Fakultäten der Universität zu Köln, 2002, p. 99.

32 Sechstes Gesetz zur Änderung des Wassershaushaltsgesetzes de 11 de noviembre de 1996. BGBl.I. 1996. p. 1690.

33 A través de esta modificación se traspuso en el ordenamiento jurídico de las aguas alemán las Directivas 85/337/CEE, y 96/61/CEE y otras de carácter medioambiental.

34 Vid. Los comentarios realizados por Kotulla en Wasserhaushaltsgesetz. Kommentar. Stuttgart. Kohlhammer, 2003, pp. 195 y ss, y por CZYCHOWSKi/ ReINHARDT en WHG. Wasserhaushaltsgesetz. Comentar, 8 Aufl, Verlag. C.H.Beck, München, 2003, pp. 348 y ss.

35 Reglamento de las aguas residuales, de 21 de marzo de 1997. Nueva redacción de 15 de octubre de 2002 (BGB1.I. p. 4047).

$36 \mathrm{Vid}$. art. 7.a).Abs. 5 WHG, cuya nueva redacción responde a la trasposición de la Directiva 96/61CEE (Vid. BGB1.I. pp. 1950 y ss). A pesar de que se emplea el concepto Stand der Technik puede ser interpretado este criterio de acuerdo con el art. 2.11 de la Directiva 96/61, en la que se utiliza el concepto de Beste Technik.
} 
Antes de continuar con el tratamiento del canon de control de vertidos estatal español es necesario ampliar el contenido, aunque sea de forma escueta, de esta Ley General Ambiental, la Ley 16/2002, de 1 de julio, que, como expresamente señala, deroga, en particular, las autorizaciones de vertidos a las aguas continentales de cuencas intracomunitarias reguladas en el Texto Refundido de 2001. En cuanto a las cuencas intercomunitarias la autorización de vertidos, otorgada hasta la entrada en vigor de dicha Ley por las Confederaciones hidrográficas, de carácter estatal, se van a integrar en la autorización ambiental integrada y son otorgadas por el órgano competente de la Comunidad Autónoma ${ }^{37}$; pero como la propia Ley 16/2002 se encarga de aclarar ello no va suponer en ningún caso un desapoderamiento de las competencias que se le atribuyen al Estado, de acuerdo con el art.149.1.22 CE, en relación con las cuencas intercomunitarias, ya que el Organismo de Cuenca estatal debe emitir un informe preceptivo acerca de la admisibilidad del vertido o, en su caso, sobre las características, condiciones y medidas correctoras, que tendrá carácter vinculante para el organismo autonómico ${ }^{38}$.

Retomando el tema de este epígrafe cuando nos referimos al canon de vertidos regulado en el art.113 TRLAg estamos, sin duda, ante un tributo de carácter estatal, creado por la Ley de Aguas siguiendo experiencias iniciadas con anterioridad en alguna Comunidad Autónoma, y que MARTín MATEO califica de tasa parafiscal ${ }^{39}$ por cuanto su destino no es un ingreso en el Tesoro, sino que es un tributo finalista cuyo devengo tiene carácter periódico y anual ${ }^{40}$, al igual que el Abwasserabgabe cuyo periodo de estimación coincide con el año natural (art.9.4),

37 Vid. L. Casado Casado, Los vertidos en aguas continentales, Comares, Granada, 2004, pp. 431 y ss.

38 Esta Ley no modifica el régimen económico financiero previsto por la legislación de aguas ni el resto de competencias que corresponden a la Administración General del Estado en materia de protección del dominio público hidráulico, ni altera tampoco las competencias relativas a vigilancia e inspección, ni la potestad sancionadora.

Sobre la integración de las autorizaciones del TRLAg en la autorización ambiental integrada, vid. A. Fortes Martín, Vertidos y calidad ambiental de las aguas. Regulación jurídico-administrativa. Atelier, Barcelona, 2005, pp. 84-90.

39 Vid. R. Martín Mateo, Manual de Derecho Ambiental, Trivium, Madrid, 1995, p. 227, y en Tratado de Derecho Ambiental. Vol. II, Trivium, Madrid, 1992, p. 88. También en este sentido B. CutAnda Lozano, Derecho... cit, p. 335.

${ }^{40}$ Con el nuevo régimen el canon del vertido se devenga el 31 de diciembre de cada año si coincide el período impositivo con un año natural, y en caso contrario se calcula el importe de dicho canon dependiendo del número de días de vigencia de la autorización, en relación con el total de días del año. Además se exige que el pago del año anterior se liquide durante el primer trimestre de cada año natural. 
concordando su periodicidad y devengo en este caso con el canon estatal español. Este carácter finalista de los tributos ecológicos ya fue introducido en 1976 en la República Federal Alemana con la aprobación de la Ley de tributos de las aguas residuales $(A b w A G)$, donde, basándose en el «principio de cobertura de costes», no se pretendía obtener un beneficio para las arcas del Estado, sino destinar la cantidad por el tributo recaudada al tratamiento de las aguas residuales, así como a la mejora de las instalaciones y de los medios técnicos. Este canon, al igual que el canon estatal español y los diferentes autonómicos, presenta tiene también una clara función incentivadora. De este modo se pretende que a través de él se ofrezcan incentivos económicos a los sujetos que realizando el vertido de aguas residuales, lo hagan disminuyendo, en lo posible, la carga contaminante de dichos vertidos. Por ello la $A b w A G$ prevé una reducción del importe del canon en aquellos casos en que el sujeto obligado a satisfacer la cuota del canon cumpla con determinados requisitos mínimos fijados en el art. 9.5 y 6 de esta Ley ${ }^{41}$. Además, determinadas inversiones realizadas para el mejoramiento de las instalaciones de las depuradoras pueden ser también compensadas y deducidas de la cuota del canon (art. 10.3 y $5 A b w A G$ ). El canon debe ser satisfecho ante los Länder, que utilizarán dichos ingresos con fines de mantener el estado cualitativo de las aguas. Una nota que diferencia este canon con el nuestro es que según el régimen marco fijado por el Bund a través del mismo se gravan los vertidos directos en las aguas y no los indirectos ${ }^{42}$ (art. 2.2), mientras que en nuestro ordenamiento jurídico, recordemos, únicamente se establece que «los vertidos al dominio público hidráulico estarán gravados con una tasa destinada al estudio, control, protección y mejora del medio receptor de cada cuenca hidrográfica, que se denominará canon de control de vertidos», enunciado que permite entender que se incluyen tanto los vertidos directos como indirectos.

En cuanto al canon español un importante cambio fue introducido tras la aludida reforma de 1999, de forma que la obligación de contribuir nace no en el momento en que es concedida la autorización del vertido, como

\footnotetext{
${ }^{41}$ Estas reducciones se elevaban hasta 1997 al 75\%. A partir de 1999 esta reducción se ha visto disminuida hasta el $50 \%$. El incentivo respondía precisamente a que la depuración de las aguas se realizase conforme al estado de la técnica exigido en el art.7.a) WHG.

${ }^{42}$ Los vertidos indirectos, en Alemania aquellos que se realizan al alcantarillado o instalaciones de depuración, son objeto de gravamen por parte del Municipios que son los obligados a eliminar las aguas residuales. En estos casos las cuotas se determinan por las ordenanzas fiscales municipales (Beitrags-Gebührensatzungen), lo que conlleva numerosas diferencias. http://www.lenntech.com/ deutsch/Abwasserverordnung-de.htm.
} 
se establecía en la Ley de Aguas de $1985^{43}$, sino en el momento en que se inicie el vertido, aunque en el cálculo de la cuota que implica este tributo sí continúe relacionado con los datos que contenga la autorización. De la misma forma en el canon de saneamiento impuesto por la Ley de tributos por aguas residuales alemana, la carga que supone el canon nace con independencia de la autorización para realizar el vertido de aguas residuales.

Vistas las características que definen este tributo, y si analizamos su evolución desde 1985, queda constatado como en la antigua Ley de Aguas el canon de vertidos se configuraba, del mismo modo que en el actual Texto de 2001, como una tasa parafiscal; no obstante, existían diferencias substanciales sobre todo en lo que al hecho imponible se refiere, que en aquélla no era otro que la realización de un vertido autorizado. Aparecía, de este modo, en un primer momento, el concepto de autorización ${ }^{44}$ como elemento de tal importancia que legitimaba, bajo las premisas de la antigua Ley de Aguas, y era suficiente para gravar una determinada conducta. Junto con esta diferencia inicial, otra, también evidente, según se desprende de la lectura del Texto Refundido, es la relativa a la convivencia, ya anunciada, entre el canon estatal y los autonómicos. Así, mientras en la Ley de 1985 se contemplaba la deducción del canon de vertido estatal de las cuotas que en concepto de canon de saneamiento aplicado por las Comunidades Autónomas viniera obligado a soportar el sujeto pasivo, esta apreciación fue suprimida en el nuevo Texto de 2001; si bien, como veremos, recientemente ha sido subsanada esta fuente de polémica. Aún así debemos aclarar planteado este supuesto que dicho procedimiento de deducción, en sentido estricto, nunca llegó a aplicarse de la manera legalmente establecida, sino que se recurrió a convenios entre las Confederaciones Hidrográficas y las diferentes Comunidades Autónomas ${ }^{45}$.

De forma general en el seno del Derecho Ambiental, y el nuestro no es una excepción, se prohíbe cualquier actividad que pueda suponer un peligro de contaminación de las aguas o degradación del dominio público

\footnotetext{
${ }^{43}$ De forma que no era el vertido en sí, sino la autorización del mismo lo que hacía aparentemente obligatoria su satisfacción, y lo que planteaba una serie de interrogantes, ya que suponía que los vertidos no autorizados no abonaban este canon, con independencia de que pudiera ponerse en marcha a posteriori un sistema sancionador por la falta de la autorización.

44 Vid. E. ROMÁn BARREIRO, «La nueva regulación en materia de vertido» en La reforma de la Ley de Aguas (Ley 46/1999, de 13 de diciembre). Embid Irujo, A. (dir), Civitas, Madrid, 2000, pp. 399 a 406, que trata las modificaciones del sistema de autorizaciones llevado a cabo por la Ley 46/1999.

45 Vid. A. LóPEZ-ViviÉ Palencia, «El canon de control de vertidos en la reforma de la nueva Ley de Aguas» en La reforma... Op. cit. p. 386.
} 
hidráulico, tanto si se realiza de forma directa o indirecta, cualquiera que sea la naturaleza del residuo, o el lugar dónde éstos se depositen. Basándose en esta prohibición cualquiera de estas actividades posiblemente contaminantes van a necesitar de una autorización de la autoridad competente $^{46}$, ya que de lo contrario se prevén sanciones y responsabilidad administrativa para el sujeto infractor. Así, mientras el Texto refundido de la Ley de Aguas se remite al régimen general del Título IX de la Ley 30/1992, de 26 de noviembre, de Régimen Jurídico de las Administraciones Públicas y del Procedimiento Administrativo Común y a lo dispuesto en su propio Título VII, la Ley de Prevención y Control Integrados de la Contaminación establece su régimen y tipifica, dentro de sus infracciones, ejercer actividades sin la preceptiva autorización ambiental, infracciones que se califican a su vez como muy graves, graves o leves según el grado de daño producido tanto al medio ambiente como a la seguridad o a la salud de las personas ${ }^{47}$, todo ello sin perjuicio de las infracciones que, en su caso, establezca la legislación sectorial y de las que puedan establecer las Comunidades Autónomas.

Como ya anunciábamos, el canon de control de vertido estatal se incardina dentro del sistema de recaudación estatal y, de la misma forma que las figuras impositivas autonómicas, está vinculado, fundamentalmente, a la prestación pública de realización de obras o actividades de tal naturaleza saneadora. La polémica distinción, al calificar el canon de vertido, entre tasa y precio público es de indudable trascendencia a la hora de determinar las consecuencias jurídicas de cada uno de ellos en general, y del canon en particular. Así, las tasas sólo pueden establecerse por o en virtud de Ley, lo que determinará su validez posterior, permitiendo esta característica la posterior concreción mediante, ahora sí, disposiciones reglamentarias o administrativas; amén de no exigirse para las tasas la existencia de una contraprestación jurídica, como ocurre con los precios públicos. El hecho generador de la misma es la prestación efectiva o potencial de un servicio público individualizado en el contribuyente y cuyo producto no debe tener un destino ajeno al servicio que constituye la razón de ser de la obligación. En relación con estos conceptos propios del Derecho Tributario y Financiero, podemos enunciar, de forma breve y meramente aclaratoria, que la diferencia radica en que con el impuesto se pretende que las personas contribuyan al sostenimiento de las cargas

\footnotetext{
46 Vid. art.100 TRLAg y art. 245 del RDPH. Téngase en cuenta la vigencia de la nueva autorización integral.

47 Vid. Ley 16/2002, Título IV «Disciplina ambiental»; y en cuanto a las infracciones y sanciones correspondientes los arts. 31 y 32 .
} 
públicas en relación con su capacidad contributiva, y con las tasas, sin embargo, se persigue que los que provocan especialmente un gasto o un perjuicio, valorable económicamente, a la colectividad, contribuyan también especialmente al sostenimiento de las cargas públicas abonando ese gasto o perjuicio, a través de una sustitución tributaria distinta de las demás, la tasa. La contribución especial por otra parte, instrumento también a tener en cuenta para evitar posibles confusiones, se legitima en la obtención por parte de los sujetos pasivos de un beneficio individual o de grupos sociales, consecuencia de la ejecución de una obra pública o de la implantación de un servicio público ${ }^{48}$.

Acerca de la clasificación de este tributo también se plantea en la doctrina alemana ${ }^{49}$, al igual que en la española, problemas sobre su naturaleza jurídica. Entiende WoLfF, en base a la Teoría de los bienes públicos ambientales, que la introducción de aguas residuales en las aguas supone un uso individual del agua. El usuario con la realización del vertido, legal o ilegal, queda exonerado de la obligación legal de eliminación de las aguas residuales, que le corresponde como dueño de las mismas. De forma que ello justifica que el disfrute de ese benéfico económico pueda ser exigido como una tasa por el uso del recurso (Ressourcennutzungsgebühr). NISIPEANU señala, por otra parte, que el canon de saneamiento alemán no es ni un impuesto, ni una tasa por la utilización de las instalaciones de aguas, ni una contribución especial, sino que debe considerarse como una «exacción especial» (Sonderabgabe) ${ }^{50}$; es decir un tributo específico derivado de un determinado uso que supone el realizar vertidos de aguas residuales, y que no se incluye dentro del ámbito de aplicación del reglamento tributario general, de este modo la carga que representa el canon nace con independencia de una autorización para realizar el vertido y tampoco representa contraprestación alguna por la utilización de las instalaciones del Municipio $^{51}$. Para completar esta alusión a la doctrina alemana, debemos evocar

\footnotetext{
48 Sobre este conflicto puede verse el artículo de G. ORÓN MORATAL, «Financiación del saneamiento y depuración de aguas residuales» en REALA, n. ${ }^{\circ} 269,1996$, pp. 9-30.

49 Sobre esta polémica, vid. Wolf, Umweltrecht., Verlag C.H. Beck, München, 2002, p. 355.

${ }^{50}$ Remitiéndonos para ello a las definiciones que de estas figuras se realizan en el art.1 de la Abgabeverordnung (AO) de 1977, art. 14 AbwAg (Abwasserabgabengesetz). Vid. «Abwasserrecht» cit. Autor, Verlag C.H. Beck. p.522. Y al pronunciamiento del tribunal constitucional alemán BVerfG, DÖV 1981, 135, y DÖV 1981, 755. Vid. también con efectos aclaratorios, la voz Abgaben en Rechtswörterbuch. Weber, K. (Hrsg), 16 Aufl, Verlag. C.H.Beck, München, 2000. También como Sonderabgabe califica este canon, R. BREUER, en Besonderes Verwaltungsrecht. Schmidt-Aßmann (Hrsg), 12 Aufl. De Gruyter Rect., Berlin, 2002, p. 568.
}

51 Vid. Abwasserrecht, Verlag. C.H.Beck, 1991, p. 523. 
también la calificación jurídica que realiza $\mathrm{SAUTTER}^{52}$. En principio este autor parte del carácter más bien jurídico que fiscal de este canon. SAUTTER destaca la excepcionalidad, frente a los impuestos, de las exacciones especiales (Sonderabgabe), no obstante reconoce que en un primer momento la calificación de este canon como Sonderabgabe, excluida su naturaleza como impuesto, puede ser válida, advirtiendo, no obstante, que el amplio concepto fiscal de impuesto (Steuer) contenido en la Constitución alemana permite aceptar que los impuestos con un fin de control sean adecuados para la afectación de la recaudación obtenida a un determinado fin. La calificación del Abwasserabgabe como tasa (Gebühr) es la preferida por los representantes de la praxis jurídico-hídrica, que destacan además el carácter de uso especial que supone el vertido de aguas residuales, en el sentido según este autor de los usos enumerados en los arts. 2 y $3 W H G$, concretando que el correcto encuadramiento del mismo sería como una tasa por uso especial (Sondernutzungsgebühr), por tanto ni impuesto, ni tampoco exacción especial, evitándose así la necesidad de una continúa y periódica revisión sobre la legitimidad de su existencia. Vistas todas estas divergencias doctrinales, que lejos están de aportar una unánime solución a esta discusión, el logro de este impuesto radica, en todo caso, en que éste fue el primer eco-impuesto establecido a nivel federal y cuyo objetivo era y es influir sobre el comportamiento de los usuarios. Pues, aunque la cantidad que supone a los usuarios el pago de este tributo no es excesivamente elevado, el carácter incentivador del mismo se manifiesta en el establecimiento de multas adicionales para en el caso en que se sobrepasen los límites fijados, las instalaciones sean deficientes, o a pesar de la modernidad de las técnicas empleadas, éstas no se utilicen correctamente. De esta forma se aseguró, ya en tiempos tempranos, el principio «quien contamina paga» ${ }^{53}$ en el ordenamiento jurídico alemán, siendo los usuarios los que asumen parte de los costes que supone usar y contaminar el agua.

Aclarados los puntos anteriores, podemos concluir que el canon del vertido, tal y como lo regula el Texto Refundido de la Ley de Aguas española, es una auténtica tasa, como afirmábamos ${ }^{54}$, pues hay una utilización

52 Vid. Einführung in das Abwasser-und Abwasserabgabenrecht, Töpner (Hrsg), Deutscher Fachschriften-Verlag, Wiesbaden, 1991, pp.1 00 y ss.

53 Verursacherprinzip o wer verschmutzt, zahlt.

54 Además de su justificación por el contenido y finalidad del canon, con la nueva redacción del art. 113 TRLAg, se reconoce expresamente en el apartado primero que el canon de control de vertidos es una tasa que grava los vertidos al dominio público hidráulico. Apoyando esta calificación de tributo, es necesario mencionar también la Ley 25/1998, de 13 de julio, de modificación del régimen legal de las tasa estatales y locales y de reordenación de las prestaciones patrimoniales de carácter público, y la Sentencia de Tribunal Constitucional 185/1998. 
del dominio público especialmente intensa que obstaculiza su disfrute general e incluso privativo; hay además un servicio público, el de depuración o eliminación provocado por el vertido y, finalmente, hay un coste precisamente por causa del vertido contaminante. Así, se revela como fundamento básico del canon el coste provocado por la contaminación, por eso la fijación de la cuota tributaria tendrá por objeto repartir entre todos el coste total de las inversiones previstas en actividades de protección y mejora de la calidad de las aguas. Y también estará ligada esa cuota, como es lógico, a los parámetros de contaminación autorizados, ya que se sigue prohibiendo los vertidos contaminantes no autorizados.

Tal y como se apuntaba el hecho imponible y, por tanto, la percepción del mismo, ya no se produce con la autorización del vertido, sino por el hecho de verter al dominio público hidráulico, pues no parecía coherente que sólo éste se aplicara cuando se era titular de una autorización, que además debía solicitar el propio interesado. Esta nueva percepción del canon, también observada en el canon alemán, que define como obligados por el mismo a «todos aquellos que realicen el vertido» (Art. 9.1 AbwAG) sin referirse a ninguna autorización, unida a la mera existencia del vertido, ha dado lugar a una visión más realista y eficaz frente a la situación anterior en la que los vertidos no autorizados, a pesar de que contaminaban tanto o más que los autorizados, no se sometían al canon, al no existir hecho imponible, sino a otro tipo de medidas. De esta forma, el infractor debía pagar el importe de una sanción pecuniaria e, igualmente, la indemnización de daños y perjuicios ocasionados, entre los que normalmente se incluía el perjuicio a que atendía el normal importe de la cuota del canon, además de estar obligado a reponer las cosas a su estado anterior.

Sujeto activo del tributo son los Organismos de Cuenca ${ }^{55}$. Es interesante al tratar este elemento, las repercusiones de la reforma de 1999, porque mientras en la antigua Ley de 1985, art.105, no se decía en ningún momento que el canon de vertido -a diferencia del canon de ocupación y de saneamiento- sería gestionado y recaudado por los Organismos de Cuenca en nombre del Estado ${ }^{56}$, tras la Ley 46/1999 se estableció que el encargado de recaudar este canon es, en el caso de cuencas hidrográficas

\footnotetext{
${ }^{55}$ Para un estudio más amplio sobre las Confederaciones hidrográficas, Vid. A. FAnLo LoRAs, Las Confederaciones hidrográficas y otras administraciones hidráulicas, Civitas, Monografías, Madrid, 1996, in totum.

${ }^{56} \mathrm{Ni}$ tampoco se especificaba que aquellos debían informar al Ministerio de Economía y Hacienda periódicamente, de forma que la diferencia entre los tres tributos radicaba en que para el caso de los vertidos era el propio Organismo de Cuenca el que actuaba como sujeto activo y no como mero delegado de la Administración de Hacienda del Estado.
} 
intercomunitarias o bien el Organismo de Cuenca o bien la Agencia Estatal de la Administración del Estado en virtud de convenio con aquél, siendo, en este último caso, el Organismo de Cuenca el encargado de transmitir al Estado los datos y censos necesarios, frente a la obligación de éste último de informarle periódicamente de la gestión realizada. Mayores complicaciones surgen cuando nos referimos a cuencas intracomunitarias dado que las Comunidades Autónomas asumen también competencias en materia de vertidos, de acuerdo con el mandato de la Disposición adicional segunda del Texto Refundido, relativa a la Administración hidráulica de las cuencas internas de una Comunidad Autónoma. Para ello es necesario que así lo establezca el respectivo Estatuto y que la cuenca hidrográfica esté comprendida íntegramente en su ámbito territorial, considerándose entonces como un tributo propio de la Comunidad Autónoma, que es titular de la potestad legislativa y de gestión sobre este tributo. Éste seria el caso en que la propia Administración Hidráulica se encargase de la gestión del canon de control de vertido. Pero si el encargado fuera la Administración Tributaria estatal, podrían plantearse ciertas dificultades, ya puestas de relieve por la profesora SETUÁrn, precisamente por el hecho de que esas cuencas se caracterizan por situarse sólo en territorio autonómico. Estas cuestiones se han reformado también por la Disposición final primera de la Ley 11/2005, que regula que «en virtud de convenio las Comunidades Autónomas podrán recaudar el canon en su ámbito territorial. En este supuesto, la Comunidad Autónoma pondrá a disposición del Organismo de cuenca la cuantía que se estipule en el convenio, en atención a las funciones que en virtud del mismo se encomienden a la Comunidad Autónoma». De la misma forma, podemos destacar aquí cierto paralelismo con la organización de la República Federal Alemana, en tanto que los encargados de recaudar la cuantía el tributo se produce precisamente a nivel de los Estados federados, esto es de los Länder.

Sujeto pasivo es, de acuerdo con lo dispuesto en el apartado segundo del art.113 del TRLAg, quienes lleven a cabo el vertido, tengan o no autorización previa. El aspecto de quién es el responsable del daño causado está directamente relacionado con la extensión y aplicación del principio «quien contamina, paga» citado. Y determinar la responsabilidad de los sujetos es una de las tareas más espinosas a las que se enfrenta la imputación de este impuesto ${ }^{57}$. Cuatro son los posibles responsables: el que realiza directamente el vertido, el productor de bienes cuyos productos contaminan, todos los que participan en la cadena de sujetos contaminantes, $\mathrm{y}$ aquel que colabora a producir la contaminación pudiendo evitarla por

57 Vid. S. Martín-Retortillo, Derecho de Aguas, Civitas, Madrid, 1997, pp. 350-351. 
sus propios medios y circunstancias. En base a este principio y a su carácter preventivo, el contaminador debe asumir los costes de las medidas de prevención de la contaminación internalizando así los costes medioambientales asociados a un producto, de forma que éstos se reflejen en el precio final del producto al igual que ya lo están los costes de transporte o envasado ${ }^{58}$. Ésta ha sido la visión defendida desde del V Programa Europeo; una visión más amplia y completa de este principio que la contenida en la Decisión de la OCDE de 26 de mayo de 1972, de modo que no sólo paga quien usa los recursos naturales, sino que se obliga también a la utilización racional de los mismos. En el caso alemán, obligados a satisfacer este tributo son pues, como adelantábamos, todos aquellos que realizan directamente vertidos de aguas residuales en las aguas superficiales o subterráneas. Estableciéndose en este caso que dichas aguas residuales están compuestas tanto de las aguas contaminadas como de las aguas provenientes de precipitaciones. Los diferentes Estados Federados pueden determinar, y así lo hacen mayoritariamente, que sean instancias intermediarias las obligadas a realizar el pago, y no directamente los particulares que realizan el vertido, que no por ello significa que estén eximidos del mismo, sino sólo que deben de satisfacerlo a las Kommune, Mancomunidades de aguas residuales, industrias o industria agrícolas ${ }^{59}$. Se contemplan del mismo modo en las regulaciones autonómicas de nuestro entorno jurídico posibilidades de excepciones a la sujeción del canon cuando por ejemplo se trate de pequeños vertidos domésticos (menos de $8 \mathrm{~m} 3$ por día), respondiendo en este caso por los vertidos las anteriores colectividades públicas.

La cuestión se complica, por tanto, a la hora de individualizar al sujeto infractor y de determinar qué y cuándo se contamina, puesto que uno de los rasgos actuales de las inmisiones a las aguas, en muchas ocasiones, es la difusión de las mismas. Por ello, dejando en un segundo plano el coste económico que suponen las medidas preventivas de los vertidos, lo que se intenta es, precisamente, particularizar y descubrir quién es el responsable de los mismos. Ante esta disyuntiva surge a colación la función pública que el art. 45.2 de la $\mathrm{CE}$ requiere para proteger la calidad de vida y del medio ambiente $\mathrm{y}$, en consecuencia, de las aguas, que exige para su eficacia la colaboración de todos los ciudadanos, tal y como se deduce del reclamo a la solidaridad colectiva, que se exige en ese mismo precepto in fine, siendo

\footnotetext{
58 Vid. A. HERLBERG, «Allgemeines Umweltverwaltungsrecht» en Umweltrecht, Koch (Hrsg), Luchterhand, 2002, p. 111.

59 Vid. Art.9.1, 2 у 3 AbwAG.
} 
precisamente esa apelación a la solidaridad colectiva ${ }^{60}$, como eje básico de colaboración en la función pública de protección del medio ambiente, la que integra este principio «quien contamina, paga» en el ordenamiento español. Paradójicamente, en Alemania el reconocimiento constitucional de este derecho al medio ambiente fue introducido en 1994, en el art.20.a) $\mathrm{GG}^{61}$ a pesar de la tradicional preocupación de este país por la protección de los recursos naturales, y de que el reconocimiento de dicho principio, como hemos visto, lo encontramos ya en la década de los setenta ${ }^{62}$. Enlazando con lo dicho en el punto anterior, entre las últimas revisiones de la política de residuos, es interesante la reforma llevada a cabo en 1997 por el Consejo ${ }^{63}$ donde se mostró la intención de ampliar el alcance del principio «quien contamina, paga», combinándolo con el principio de «responsabilidad compartida», ya que en opinión del Consejo «todos los agentes económicos, incluidos los fabricantes, importadores, distribuidores y consumidores, deben cargar con su parte específica de responsabilidad, en lo que se refiere a la prevención, valorización y eliminación de los residuos». No obstante, hemos de advertir que, desde diferentes análisis $^{64}$ acerca de la vertiente económica, financiera y tributaria del tema de la contaminación, se ha cuestionado hasta qué punto la asunción del coste que la descontaminación plantea debe ser considerada una carga económica a soportar por quien o quienes producen el deterioro de los recursos o esa carga debe ser asumida con carácter general por la comunidad mediante impuestos, ya que estos sujetos, sin beneficio alguno, han tenido incluso que soportar, con anterioridad, el deterioro medio ambiental. Otra de las opciones planteada, incluso curiosa, es la fórmula establecida en el sistema americano de los llamados «certificados de uso del medio ambiente» ${ }^{65}$. Recordar que en

\footnotetext{
60 Como señala Rosembus: la solidaridad colectiva no es otra cosa que el interés general. El mismo valor protegido en el art.128 de la CE, reaparece en el art.45 CE, en los términos de interés difuso colectivo al equilibrio ecológico y, también, asignado el coste social que este significa. Vid. Los tributos y la protección del medio ambiente, Marcial Pons, Madrid, 1995, p. 43.

61 Vid. J. KocH, (Hrsg). Umweltrecht, Op.cit, pp. 63 y ss.

62 Cfr. Supra.

63 Vid. Punto n. ${ }^{\circ}$ 13. Resolución del Consejo de 24 de febrero de 1997, sobre una estrategia comunitaria de gestión de residuos. DOCE C 76, de 11 de marzo de 1997.

${ }^{64}$ Nos referimos sobre todo a planteamientos económicos neoliberales que abordan el tema de la contaminación de las aguas incluso desde un punto de vista del mercado. Vid. T.L. ANDERsOn, Ecología de mercado, Leal, Madrid, 1993.

65 Esta última opción supone que la Administración fija de forma casuística los niveles máximos de contaminación permitidos en cada curso de agua. Conforme a ellos emite los correspondientes «cer-
} 
relación con la aplicación del principio que nos interesa, la diferencia fundamental de las medidas que éste supone y que lo caracteriza es como ya hemos tratado la individualización del sujeto responsable del hecho mismo de la contaminación.

El Organismo de Cuenca aunque realice actividades contaminantes no estará sujeto al canon, ya que la concurrencia entre sujeto pasivo y activo no es posible, además de no operar, con respecto a él, el requisito de autorización administrativa para realizar vertidos, de forma que los suyos no generan hecho imponible. Ahora bien, el coste que genere su contaminación no será tenido en cuenta a la hora de fijar el valor de la unidad de contaminación, de modo que no recaerá sobre el conjunto de titulares de autorización del vertido.

En cuanto a la cuantificación del tributo únicamente destacaremos la principal novedad que radica en el cálculo del precio unitario; éste se obtendrá, a partir de ahora, multiplicando un precio denominado básico por un coeficiente de mayoración o minoración, que será establecido en el Reglamento que desarrollará la Ley ${ }^{66}$. La importancia radica en que a través de este coeficiente, que está condicionado por la naturaleza, características y grado de contaminación del vertido y por preservar la mayor calidad ambiental del medio físico en que se vierte, se persigue defender, particularmente, la calidad del curso donde se realiza el vertido y, en general, la del dominio público hidráulico, en contraposición a la regulación anterior, donde el fin principal era que ante todo que se pagase por los titulares de las autorizaciones el canon. De esta forma se consigue una mayor y mejor adaptación de nuestro ordenamiento jurídico a las directivas comunitarias vigentes en esta materia, pues a la vez que se basa en el principio «quien contamina, paga», se incentiva que quien contamine menos, pueda ahorrar. En el caso alemán, el impuesto referido grava también la «lesividad» que supone la producción de aguas residuales, «lesividad» que viene determinada basándose en una «unidad de contaminación» ${ }^{67}$, de forma que cuando menor sea el daño causado menor es también la cuan-

tificados de uso de medio ambiente» que son títulos libremente negociables en el mercado y que permite contaminar en la cuantía en ellos establecida. Vid. S. MARTín-RETORTILLo, nota 94, p. 353 en Derecho...cit.

${ }^{66}$ Para el caso de vertidos autorizados nos remitimos a lo dispuesto en el art. $291 \mathrm{RDPH}$, en la redacción dad por el RD. 606/2003, de 23 de mayo. Este artículo se refiere a su vez, para la determinación del coeficiente de mayoración o minoración, al anexo IV del Reglamento. Si los vertidos son no autorizados el importe se calculará de acuerdo a lo establecido en el art. 292 RDPH.

${ }^{67}$ Cuyo valor, desde el 2 de enero de 2002, es de 35,79 euros. 
tía del tributo. En este caso la cuota del tributo se calcula en relación con la cantidad y a la nocividad de los componentes específicos vertidos en el agua.

En todo caso, la Ley de Aguas, a diferencia de lo que ocurre con el principio «quien contamina, paga», no recoge ninguna exención al canon de vertido, ya que es lógico que quien contamine deba colaborar con el coste de las actividades previstas en los Planes Hidrológicos para mejorar la calidad de las aguas. La Ley matiza, únicamente, el régimen del canon de vertidos señalando que sí existe posibilidad de que existan supuestos excepcionales que den lugar a que se otorguen ayudas y subvenciones, pero no exenciones legítimas en sentido estricto. Al respecto presenta divergencias la solución alemana, ya que en su Ley de impuestos por aguas residuales, se prevé que determinados supuesto estén exentos del pago de este canon, supuestos que en el caso de los estados federados viene determinados por sus propias leyes, siempre dentro de los límites fijados en el art. 10.2 de la Ley de impuestos por aguas residuales estatal y que se concretan en los siguientes (art. 10.1):

- Agua contaminada que no supone, para la contaminación ya existente por el vertido, una mayor nocividad.

- Agua contaminada procedente de la supresión de materias primas minerales.

- Agua contaminada procedente de embarcaciones.

- Precipitaciones procedentes de superficies industriales y de las vías ferroviarias, cuando no se efectúen sobre la red pública de canalización.

- Y, aunque no se formule expresamente como una excepción, deben también entenderse incluidos, según el contenido de la ley, aquellos casos en que las concentraciones de contaminación sean tan escasas que el legislador considere oportuno la exención a este impuesto.

\section{CONCURRENCIA ENTRE EL CANON ESTATAL Y LOS CÁNONES DE SANEAMIENTO AUTONÓMICOS}

La polémica surgida en relación con este tema se hizo más evidente con la aprobación del Texto Refundido de la Ley de Aguas y con el 
nuevo canon de control de vertidos estatal que regula. Ello porque, si bien anteriormente el hecho imponible venia determinado por la existencia de una previa autorización, en el Texto de 2001 el hecho imponible lo constituye el vertido de aguas residuales reflejado en el consumo de agua, que es precisamente la causa que da lugar al pago de los cánones autonómicos.

El canon del vertido del artículo 113 del TRLAg es de carácter estatal, pero en este mismo artículo, apartado $7^{\circ}$, se reconocía y reconoce la existencia de otros, al referirse a los cánones de carácter autonómico y local, y de los que a su vez declara su total independencia. Se trata de exacciones establecidas para financiar el saneamiento coincidentes por tanto de forma parcial con el canon estatal anteriormente visto.

Algunos de los cánones autonómicos ya fueron establecidos con anterioridad a la aprobación de la Ley de Aguas de 1985, por dos Comunidades. En primer lugar, por Cataluña, a través de la Ley 5/1981 sobre Desarrollo Legislativo en Materia de Evacuación y Tratamiento de Aguas Residuales ${ }^{68}$ revisada substancialmente por la Ley 17/1987, en la que se disponía que «las obras y servicios de evacuación, tratamiento y recuperación de las aguas residuales correspondientes a los planes y proyectos aprobados, se financiarán con cargo a los recursos obtenidos por aplicación del régimen económico establecido en esta ley». El régimen económico establecido se nutria de dos impuestos: el incremento de tarifas de saneamiento y el canon de saneamiento para usos domésticos o industriales del agua, que serian aplicables en el territorio que, con esa finalidad, se hubiera determinado al aprobar los planes y proyectos de saneamiento $^{69}$. Por Decreto 320/1990, de 21 de diciembre, se aprobó el Reglamento regulador del incremento de tarifa y del canon de saneamiento. Además de estas exacciones la Ley 5/1990 de 9 de marzo, de infraestructuras hidráulicas de Cataluña, creó como ingreso específico del régimen económico-financiero de las obras y actuaciones reguladas en esa ley «el canon de infraestructuras hidráulicas» de posible aplicación a las obras relacionadas con los vertidos ${ }^{70}$.

\footnotetext{
68 La constitucionalidad de la Ley catalana fue puesta en duda por M. ÁlVAREZ Rico, en «Reflexiones sobre la Ley de la Generalidad de Cataluña de 4 de junio de 1981 sobre desarrollo legislativo en materia de evacuación y tratamiento de aguas residuales» en $R A P, 1981,{ }^{\circ}{ }^{\circ}$, pp. 409 y ss.

69 Vid. Arts. 33, 39, 51, 53 y 57 de la Ley 17/1987, de 13 de julio.

70 Estos cánones fueron sustituidos por el llamado «canon del agua» que creó la Ley 6/1999, hoy derogada, y que se regula en el Decreto 103/2000, de 6 de marzo (DOGC de 13/03/00).
} 
Esta iniciativa fue seguida, en segundo lugar, por la Comunidad de Madrid, que aprobó la Ley 17/1984 reguladora del Abastecimiento y Saneamiento de Agua, donde se preveía una «cuota suplementaria» ${ }^{71}$ a las tarifas de abastecimiento de agua y saneamiento, destinadas a la financiación de obras de infraestructura y actuaciones medioambientales relacionadas con la calidad del agua.

En la actualidad casi la totalidad de Comunidades cuentan con tributos de tal naturaleza ${ }^{72}$. Así, Navarra creó el canon de saneamiento mediante la Ley Foral 10/1988, de 29 de diciembre de Saneamiento de las Aguas Residuales, que se exige por el vertido de aguas residuales ya sea directamente o a través de las redes de alcantarillado de las Entidades Locales ${ }^{73}$; en la Comunidad Valenciana se aprobó la Ley 2/1992, de 26 de marzo, del Gobierno Valenciano, de saneamiento de las aguas residuales de la Comunidad Valenciana ${ }^{74}$, en Galicia la Ley 8/1993 de 23 de junio, reguladora de la Administración Hidráulica, recoge también la figura del canon de saneamiento destinado a financiar los gastos de inversión y explotación de infraestructuras de evacuación «alta» y de tratamiento de aguas residuales $^{75}$. Otras Comunidades que han establecido estos cánones son la Comunidad Balear por Ley 9/1991, de 27 de noviembre ${ }^{76}$; el Principado de Astu-

71 Vid. Art.11.3 de dicha Ley (BOCM de 31/12/84). Esta ley fue desarrollada por el Decreto 137/1985, de 20 de diciembre (BOCM de 11/01/86).

72 De manera paradójica, Andalucía, una de las Comunidades mas castigadas en nuestro país por la escasez de agua, y la falta de recursos económicos destinados a la inversión en obras hidráulicas que permitan una mayor un mejor aprovechamiento de las mismas, no posee todavía un canon de saneamiento, al respecto y como propone J.M. CASTILLO LÓPEZ, vid. «Un canon de saneamiento y depuración de aguas residuales para Andalucía», disponible en http:/www.cica.es/aliens/gimadus/JOR-CA-3.html.

73 Vid. Arts. 9 y ss. de la Ley Foral 10/1988. Desarrollada por el Decreto foral 82/1990, de 5 de abril (BON de 28/03/90).

${ }^{74}$ Desarrollada por el Decreto 266/1994, de 30 de diciembre, del Gobierno Valenciano, por el que se aprueba el Reglamento sobre Régimen Económico-Financiero y Tributario del Canon de Saneamiento. (DOGV de 31/12/94). Modificado por el D.193/2001, de 18 de diciembre (DOGV de 21/12/01). Sobre ésta última modificación, vid. F. EsCRIBANo ROMERO, «Las modificaciones del Canon de Saneamiento de Aguas Residuales», 2001, disponible en: http://ecoforo.cepymev.es/jornadas/Ponencias/2002/Canon\%20de\%20Saneamiento.pdf.

75 Vid. Arts. 33 y ss. de esta Ley. El capítulo IV de esta Ley fue desarrollado por el Decreto 8/1999, de 21 de enero, por el que se aprueba el Reglamento de desarrollo legislativo relativo al canon de saneamiento. (DOG de 01/02/99, corrección de errores DOG de 20/02/99). Modificado por el Decreto 265/2000, de 26 de octubre (DOG de 10/11/00).

${ }^{76}$ Ley que ha sido posteriormente modificada por el artículo 1 de la Ley 4/1994, de 29 de noviembre, (BOIB de 17/12/94). El reglamento del canon de saneamiento se aprobó por el Decreto 132/1995, de 12 de diciembre, (BOIB de 21/12/95), desarrollado por Orden de 14 de diciembre de 1995. 
rias, Ley 1/1994, de 21 de febrero, sobre abastecimiento y saneamiento ${ }^{77}$; la Rioja con la Ley 7/1994, de 19 de julio, y la Ley 5/2000, de 25 de octubre, de saneamiento y depuración de Aguas Residuales ${ }^{78}$; Aragón con la Ley 6/2001, de 17 de mayo, de Ordenación y Participación de la Gestión del Agua en Aragón ${ }^{79}$, y más recientemente la Comunidad Autónoma de Murcia aprobó por Ley 3/2002, de 20 de mayo, de Tarifa del Canon de Saneamiento ${ }^{80}$, así como Cantabria, Ley 2/2002, de 29 de abril, de Saneamiento y Depuración de las Aguas Residuales.

Todos estos cánones autonómicos fueron inicialmente, y de forma paradójica, impulsados por el Gobierno estatal, ya que era el propio Plan Nacional de Saneamiento y Depuración de $1995^{81}$ el que, en parte, contenía la obligación de que las Comunidades Autónomas aplicasen un canon de saneamiento para, así, hacer frente a las actuaciones derivadas de la implantación de la Directiva 91/271/CEE, de 21 de mayo de 1991, sobre el Tratamiento de las Aguas Residuales Urbanas ${ }^{82}$. En vista de este requisito el antiguo artículo 105 de la Ley de Aguas de 1985, en su apartado cuarto ${ }^{83}$, establecía una fórmula, de carácter en cierto modo compensatorio, que permitía reunificar las distintas exacciones que, aún con títulos distintos, pudieran gravar los vertidos y que no estaba generalizada, auto-

\footnotetext{
77 Desarrollada por el RD. 19/1998, de 23 de abril, por el que se aprueba el Reglamento de desarrollo de la Ley 1/1994, de 21 de febrero, sobre abastecimiento y saneamiento de aguas en el Principado de Asturias (BOPA de 5/05/98) y modificada por la Ley 18/1999, de Medidas Presupuestarias, Administrativas y Fiscales del Principado de Asturias (BOPA de 31/12/99).

${ }^{78}$ Decreto 42/1997, de 22 de agosto, por el que se aprueba el reglamento sobre el régimen económico-financiero y tributario del canon de saneamiento (BOR de 23/08/97).

${ }^{79}$ El canon de saneamiento está regulado por Decreto 266/2001, de 6 de noviembre, del Gobierno de Aragón, por el que se aprueba el Reglamento Regulador del Canon de Saneamiento de la Comunidad Autónoma de Aragón (BOA de 30/11/01).

${ }^{80}$ Desarrollada por el Decreto 102/2002, de 14 de Junio, por el que se aprueba el Reglamento del Régimen Económico-financiero tributario, del canon de saneamiento de la Región de Murcia (BOR de $18 / 06 / 02)$.

${ }^{81}$ Aprobado por Acuerdo del Consejo de Ministros de 17 de febrero de 1995. BOE de 12 /05/95.

${ }^{82}$ Esta Directiva, emitida con el fin de asegurar el mantenimiento y recuperación de las aguas urbanas, si bien obliga al Estado debía ejecutarse por cada Comunidad, de forma que el uso urbano de las aguas no afectara negativamente al medio ambiente. Junto con este ideal se pretendía eliminar, al mismo tiempo, el traspaso de aguas residuales de unos Estados a otros.

${ }^{83}$ Art. 105.4 LAg: «4.Cuando el sujeto pasivo del canon del vertido viniera obligado a soportar otras cargas económicas, ya establecidas o que puedan serlo por las Comunidades Autónomas o por las Corporaciones locales, en el ejercicio de sus competencias, para financiar planes o programas públicos de depuración de aguas residuales, el Consejo del Agua determinará anualmente las deducciones que deban realizarse en el importe del canon de vertido».
} 
rizando en principio a que las Confederaciones Hidrográficas percibieran y administraran directamente el importe de las «cuotas suplementarias a las tarifas de abastecimiento» o de las «tarifas o cánones de saneamiento» sancionadas en algunas Comunidades Autónomas; conclusión que se extraía de la interpretación sensu contrario del artículo $105.3^{84} \mathrm{LAg}$ de $1985^{85}$. Las posteriores reformas suprimieron toda referencia a estos apartados y a la posibilidad de conjuntar las distintas exacciones, estatales y autonómicas, poniendo fin a la situación, desfasada, que se mantenía en el régimen anterior; ya que en realidad, la práctica de la solución seguida en el régimen de 1985, ha demostrado que fue bastante divergente a lo descrito en las líneas precedentes, puesto que las encargadas de cobrar íntegramente estos tributos fueron las Comunidades Autónomas mediante Convenios suscritos entre las Confederaciones y los Gobiernos autonómi$\cos ^{86}$ asumiendo éstos el compromiso de dedicar la totalidad de su importe a obras de depuración y saneamiento de unos recursos sobre los que, paradójicamente, éstos no poseen titularidad y que, por tanto, no les correspondería administrar. Aún así, puede legitimarse esta «potestad» en la lógica que exige que sean los cursos de agua donde se genera ese canon el destino de las inversiones a realizar.

De todas formas, la nueva redacción de art.113. $7^{\mathrm{a}}$ TRLAg fue criticada porque la declaración que en este apartado se realizaba sobre la independencia del nuevo tributo «de los cánones o tasas que puedan establecer las Comunidades Autónomas o Corporaciones locales para financiar las obras de saneamiento y depuración», no se acompañaba, si quiera, de la previsión de eventuales supuestos de concurrencia con los tributos autonómicos, y no excusaba tampoco para suprimir el propio derecho a la deducción, sobre todo llegado este punto en que, como hemos visto las finalidades del canon estatal y de los autonómicos van a ser coincidentes, a la vez que estos cánones se han revelado como imprescindibles para coadyuvar a la financiación de dichas actuaciones de saneamiento y depuración, demostrándose claramente que su recaudación por las Comunidades

\footnotetext{
${ }^{84}$ Art. 105.3 LAg: «3. Este canon será percibido por los Organismos de cuenca y será destinado a las actuaciones de protección de la calidad de las aguas que hayan sido previstas en los planes hidrológicos de cuenca, a cuyo efecto se pondrá a disposición de los Organismos competentes».

85 Sobre la situación derivada tras la aprobación de la Ley de Aguas de 1985, y con anterioridad a su reforma de 1999, me remito a los comentarios de S .Martín-Retortillo en Derecho... Op. cit, pp. 357 y ss; J. Ma. Quintana Petrus, Derecho de Aguas, Bosch, Barcelona, 1989, pp. 528-544.

${ }^{86}$ Convenios que se presentan también actualmente como una de las soluciones para aquellos casos en que en las cuencas intercomunitarias quien lleve a cabo el control de los vertidos sea la Administración hidráulica autonómica. Acompañados, claro está, dichos convenios de la correspondiente transferencia de recursos estatales con cargo al canon de control de vertidos.
} 
Autónomas es muchísimo más eficaz que la derivada del canon de vertidos estatal ${ }^{87}$.

La situación se ha visto en cierto modo subsanada con la reforma del Texto Refundido de la Ley de Aguas de 2005 que supuso la introducción de un nuevo apartado octavo en el que se dice: «cuando un sujeto pasivo del canon de control de vertidos esté obligado a satisfacer algún otro tributo vinculado a la protección, mejora y control del medio receptor establecido por las Comunidades Autónomas en ejercicio de sus competencias, el importe correspondiente a este tributo se podrán deducir o reducir del importe a satisfacer en concepto de canon de control de vertidos. Con el objeto de arbitrar los mecanismos necesarios para conseguir la efectiva correspondencia entre los servicios recibidos y los importes a abonar por el sujeto pasivo de los citados tributos, el Ministerio de Medio Ambiente y las Administraciones autonómicas implicadas suscribirán los oportunos convenios de colaboración ${ }^{88}$. Se adopta pues una solución similar a la que ya de manera premonitoria había establecido Cataluña en su anterior Ley 6/1999; pero en el caso catalán la deducción se plantea respecto del canon del agua autonómico regulado en el art. 62 del Decreto Legislativo 3/2003, de 4 de noviembre, de donde se sustraerá la cantidad que se haya satisfecho en concepto de canon de control de vertidos.

\section{CONCLUSIONES}

Basándonos en lo expuesto en líneas precedentes podemos concluir con dos reflexiones. En primer lugar, el importante esfuerzo de adaptación con el que nuestro Derecho de Aguas está respondiendo a las exigencias comunitarias, como evidencian las sucesivas reformas de nuestros textos básicos sobre aguas. Y, en segundo lugar, la necesaria coordinación que, ya en el ámbito interno, se exigen en el seno de las políticas ambientales y que requieren de acciones conjuntas entre Comunidades Autónomas y el Estado, pues es la forma más eficaz de prevenir la contaminación de los recursos hídricos.

\footnotetext{
87 Vid. A. LÓPEZ-VIVIÉ PALENCIA, «El canon de control...», cit., p. 391.

${ }^{88}$ Añadido por la Disposición final primera de la Ley 11/2005, de 12 de junio.
} 